\title{
Foreword to the First Edition
}

The negotiations leading to the Montreal Protocol on protection of the ozone layer, so perceptively described and analyzed by Ambassador Richard Benedick in this volume, are a major manifestation of a new dimension in dipomacy.

Throughout most of the twentieth century, diplomats have concentrated on questions of political and economic relations among nationstates, the traditional subjects of diplomacy. In the period following World War II other issues arose, spurred by the information revolution, the development needs of newly independent nations, and technical advances in nuclear energy and electronics. As the century closes, a third set of international problems--those relating to the health of the planet-is coming to the fore, presenting new challenges to diplomacy.

These problems will test the ability of governments and their diplomats to organize themselves for new dimensions in foreign relations, and to negotiate agreements that require departures from the traditional nation-state orientations of diplomacy toward patterns of global management still to be developed. The threatened depletion of the Earth's ozone layer is a prime example of such challenges. Similar items on the new agenda include global warming, the destruction of forests, the unprecedented extinction of plant and animal species, expanding desertification and soil erosion, and the pollution of such common resources as the oceans, the atmosphere, and the Antarctic continent.

Diplomats and governments alike may find this set of issues as difficult to manage and negotiate as any issues of peace or war. Because solutions to the problems of the environment must be global, they will present an unprecedented challenge to concepts of national sovereignty. As the ozone negotiations demonstrated, solutions will have to involve broad cooperation rather than competition among nation-states-perhaps eventually even new organizations that supersede the nation-state. Diplomatic efforts must also address divisive differences in perspective between the northern industrialized nations and the poorer nations of the Southern Hemisphere.

Environmental negotiations affect, too, the delicate relationship between the public and private sectors. Ways must be found to improve 
the coordination of the actions and policies of multinational corporations with those of governments. And the technical complexity of the problems makes them politically exploitable. These factors increase the difficulties of gaining public and legislative support for the kinds of hard decisions that must be made. The role of science advisers to governmental leaders becomes increasingly significant.

The tasks now facing diplomats and decision makers seeking to resolve world problems are complex but not hopeless. Five years ago, for example, few would have predicted the improvement in U.S.-Soviet relations. Patient and persistent diplomacy, multilateral pressures, and recognition of the futility of continuing conflict have brought results. Now diplomatic approaches to global environmental issues are beginning to yield results, even though the seriousness of the problems has been widely recognized only in the last decade. Such results become possible when a broad public recognition of the unacceptability of conditions creates pressure on governments to act. Only when that pressure makes itself felt in executive offices and legislatures will the new items on the global agenda assume equivalent prominence with matters of war and peace and the dramatic changes brought about by the communications revolution.

In this context, the achievement of the ozone treaty was a major breakthrough. In this age of high-technology communications and computers, it is easy to overlook the function of the diplomat. The story of the Montreal Protocol, however, demonstrates convincingly that negotiating success is still highly dependent on the imagination and skills of professional diplomats.

Richard Benedick has had years of diplomatic and negotiating experience as a career officer of the U.S. Foreign Service. As deputy assistant secretary of state for environment, health, and natural resource issues, he was assigned by Secretary of State George Shultz to coordinate U.S. preparations for a protocol on protecting the ozone layer and to be its chief U.S. negotiator. Designing and implementing an innovative negotiating strategy against heavy odds, Ambassador Benedick played a crucial leadership role in the internationl process. In recognition of his work in securing this historic treaty, he received in 1988 the highest career public service honor, the Presidential Distinguished Service Award. Richard Benedick's contribution is an example of how one individual's vision and commitment can be critical to effective modern diplomacy.

David D. Newsom

Former U.S. Under Secretary of State for Political Affairs 